BULLETIN Bulletin hispanique

HISPANIQUE Université Michel de Montaigne Bordeaux

120-1 | 2018

Varia

Armando Palacio Valdés a través de la mirada de Rafael Altamira

Armando Palacio Valdés vu par Rafael Altamira

Armando Palacio Valdés seen by Rafael Altamira

$M^{a}$ de los Ángeles Ayala

(2) OpenEdition

Journals

Edición electrónica

URL: https://journals.openedition.org/bulletinhispanique/5968

DOI: 10.4000/bulletinhispanique.5968

ISSN: $1775-3821$

Editor

Presses universitaires de Bordeaux

Edición impresa

Fecha de publicación: 30 junio 2018

Paginación: 257-270

ISBN: 979-10-300-0298-0

ISSN: 0007-4640

Referencia electrónica

$\mathrm{M}^{\mathrm{a}}$ de los Ángeles Ayala, «Armando Palacio Valdés a través de la mirada de Rafael Altamira», Bulletin

hispanique [En línea], 120-1 | 2018, Publicado el 01 enero 2022, consultado el 08 enero 2022. URL:

http://journals.openedition.org/bulletinhispanique/5968 ; DOI: https://doi.org/10.4000/

bulletinhispanique.5968 


\title{
Armando Palacio Valdés a través de la mirada de Rafael Altamira
}

\author{
$M^{a}$ DE Los Ángeles Ayala \\ Universidad de Alicante - España
}

Cette étude propose l'analyse des textes critiques, parus dans la presse ou en volume, que l'œuvre romanesque de Palacio Valdés a inspirés à Rafael Altamira. Elle s'appuie aussi sur la correspondance, méconnue, conservée à la Residencia de Estudiantes et au Centro de Interpretación Armando Palacio Valdés. Altamira tient Palacio Valdés pour l'un des grands romanciers du réalisme-naturalisme espagnol.

Mots-clés : XIX ${ }^{\mathrm{e}}$ siècle, critique littéraire, roman, correspondance, Rafael Altamira, Armando Palacio Valdés.

En el presente artículo se analizan las aportaciones críticas, recogidas en volumen y en la prensa, que Rafael Altamira realiza sobre el corpus novelístico de Armando Palacio Valdés. Asimismo se tiene en cuenta el desconocido epistolario conservado en la Residencia de Estudiantes y en el Centro de Interpretación Armando Palacio Valdés. Altamira sitúa a Palacio Valdés entre los grandes novelistas del realismo-naturalismo español.

Palabras clave: Siglo XIX, crítica literaria, novela, epistolario, Rafael Altamira, Armando Palacio Valdés.

This article discusses the Rafael Altamira's critical contributions on the Palacio Valdes' novelistic corpus, collected both in volume and in the periodical press. The unknown correspondence preserved in the Residencia de Estudiantes and in The Interpretation Center "Armando Palacio Valdés» is also considered in this work. Altamira placed Palacio Valdés among the best Spanish realismo-naturalismo novelists.

Keywords: Nineteenth century, literary criticism, novel, correspondence, Rafael Altamira, Palacio Valdés. 
$\mathrm{C}$ uando Armando Palacio Valdés publica su primera novela en 1881, El señorito Octavio, Rafael Altamira iniciaba, asimismo, su carrera oficial en el mundo de las letras impresas ${ }^{1}$ al dar a conocer en un periódico alicantino $L a$ Antorcha, Gazul el guerrillero, Un problema de amor y La piel del estelión ${ }^{2}$, tres relatos cortos que muestran de forma clara una vocación literaria que nunca le abandonaría, que siempre pugnó con su rotunda y exigente tarea como jurista, pedagogo e historiador que tantos frutos proporcionará a la sociedad española. Rafael Altamira en septiembre de 1881, con quince años de edad, se traslada a Valencia para cursar la carrera de Derecho, sin que dichos estudios le impidan mantener una atenta mirada al mundo literario. De hecho contamos con numerosos testimonios que dan fe de sus vacilaciones entre la literatura, la filosofía y el derecho ${ }^{3}$, vacilaciones que se extienden hasta el año 1907, cuando anuncia en el prólogo de Fantasías y recuerdos su decisión de abandonar la creación literaria y reservarse una parcela de su amor a la literatura a través del ejercicio de la crítica ${ }^{4}$. Entre la lectura de textos jurídicos y libros filosóficos e históricos, Altamira en estos años universitarios siempre tendrá tiempo para la amena literatura, participando junto a Vicente Blasco Ibáńez en enriquecedoras tertulias, en las que se comentaban las novedosas obras que iban apareciendo en aquellos ańos, a la vez que colabora en periódicos alicantinos y valencianos.

1. Con anterioridad Altamira había fundado en 1872, a los doce años de edad, una revista literaria manuscrita titulada La Ilustración Alicantina, cuya publicación se dilata, precisamente, hasta el año 1881. En la última página de la revista aparece la siguiente información: $L a$ Ilustración Alicantina. Revista de Ciencias, Arte, Historia, Literatura, Modas, etc. y de actualidad. Sale un $n^{\circ}$ de 16 págs. Con infinidad de grabados los días 1 y 20 de cada mes. Se publican Suplementos. Dirigirse a la Adm. San Pascual, 5. El Director gerente - R. Altamira.

2. «Gazul el guerrillero». La Antorcha. Periódico cientifico, literario y de intereses materiales, Año I, 16 (7 de julio) y 17 (17 de julio). «Un problema de amon», Año I, I. 22 (13 de septiembre), 23 (19 de septiembre) y 24 (29 de septiembre). «La piel del estelión», Año I. 29 (20 de noviembre). El semanario alicantino La Antorcha comenzó a editarse en febrero de 1881, finalizando su publicación en agosto de 1882. A partir de este momento adopta el nombre de El Álbum. Era propiedad de Bernardo Sempere y en julio de 1881 Altamira ingresó en la redacción del mismo.

3. Vacilaciones que se pueden observar en la correspondencia que mantiene con su amigo Pascual Soriano Roca, pues en carta del 16 de septiembre de 1882, confiesa que "Tengo pretensiones de filósofo, y filósofo por todo lo alto...», apud. Vicente Ramos, Rafael Altamira, Madrid, Alfaguara, 1968, p. 28. No obstante, a la altura de 1885, en carta fechada el 2 de enero de dicho ańo, afirma lo siguiente: «iAbajo los libros de Derecho y arriba las Estéticas! No estudio una palabra de procedimientos ni pienso estudiar. Literatura y basta», Ibid., p. 29.

4. Altamira afirma en el párrafo del prólogo que reproducimos el deseo de continuar, pese a renunciar a la creación literaria, ejerciendo como crítico literario: «Una sola excepción me reservo, y es la de la crítica; y esa, porque la crítica de las obras ajenas es también Historia, y porque representa, además, el único sustitutivo de la producción en que ceso, la única válvula por donde puedo escapar de vez en cuando, en la contemplación de la poesía que otros expresan, y sin que nadie alarme, algo de la que sigue cantando en el fondo de mi alma", Fantasías y recuerdos, Alicante, Imprenta de Hijos de V. Costa, 1910, p. 13. No obstante, Altamira nunca renunciará por completo a la creación, publicando en diversos periódicos esbozos narrativos que serán recogidos parcialmente en sus obras Cartas de hombres (1927-1941), Lisboa, LivrariaLuso-Espanhola, 1944, Tragedias de algunos y de todos y Elegias, México, Ediciones Mideterrani, 1948 y Máximas y reflexiones, México, Ediciones Mediterrani, 1949. 
Es, precisamente, en uno de estos periódicos alicantinos donde encontramos el primer trabajo que Altamira dedica a su admirado Palacio Valdés, artículo que no fue recogido entre los que figuran en Tierras y hombres de Asturias (1949)5. El artículo al que nos estamos refiriendo lleva como título «La última novela de Palacio Valdés» y apareció el 27 de septiembre de 1883 en el periódico Las Germanías de la ciudad de Alicante ${ }^{6}$. Si traemos a colación esta colaboración es con la intención de situar correctamente el inicio del interés que siempre despertaron las novelas del escritor asturiano en el ánimo de Altamira, pues la indicación del propio crítico alicantino al señalar que "Riverita» es el primer artículo que dedica a Palacio Valdés ${ }^{7}$ ha dado a pie a retrasar hasta 1886 la atención crítica de Altamira hacia Palacio Valdés. Es, pues, Marta y María la novela que inicia la serie de reseñas críticas que se dilatan por espacio de un amplio marco temporal, de 1883 a 1924.

Dado el estado en que se encuentra la recuperación de las colaboraciones de Altamira en la prensa española, europea e hispanoamericana ${ }^{8}$, nos detendremos, fundamentalmente, en los seis artículos que el propio Altamira recogió en su libro Tierras y hombres de Asturias ${ }^{-}$"Don Armando Palacio Valdés.

5. Tierras y hombres de Asturias, México, Revista Norte, 1949. En nuestro trabajo citamos por Rafael Altamira. Tierras y Hombres de Asturias, Xuan Cándamo (ed.), con prólogo de David Ruiz. Oviedo. KRK Ediciones-Universidad de Alicante-Universidad de Oviedo, 2004.

6. «La última novela de Palacio Valdés», Las Germanías, 27 de septiembre de 1883. Vicente Ramos, en Palabra y pensamiento de Rafael Altamira, Alicante, Caja de Ahorros de Alicante y Murcia, 1987, p. 56, recoge esta reseńa crítica. No obstante debemos señalar que tras infructuosas búsquedas en instituciones provinciales y nacionales no hemos conseguido hallar ningún ejemplar correspondiente a esta fecha.

7. Rafael Altamira al incluir el artículo "Riverita» en Tierras y hombres de Asturias, op. cit., p. 212, señala en nota a pie de página lo siguiente: «Este fue el primer artículo sobre las novelas de Palacio Valdés que escribí en Valencia, en el último año de mi licenciatura». Es obvio que el crítico alicantino ha olvidado, dado el paso del tiempo, el artículo que dedicó a Marta y María en las Germanias.

8. Durante los últimos años un grupo de investigadores del Departamento de Filología Española de la Universidad de Alicante, dirigidos por el profesor Enrique Rubio Cremades, viene trabajando en la recuperación del material disperso de Rafael Altamira en la prensa espańola, europea e hispanoamericana. Dicho grupo ha gozado de los siguientes proyectos: $\mathrm{I}+\mathrm{D}$ de la Generalitat Valenciana "La labor periodística de Rafael Altamira (GV06/043) y I+D+i del Ministerio de Cultura» (FFI200865226).

9. Vid. a este respecto el análisis que de estos seis artículos lleva a cabo $M^{a}$ Corpus Requena en su tesis doctoral Rafael Altamira, critico literario (2002). http://www.cervantesvirtual.com/ obra/rafael-altamira-critico-literario--0/ En Tierras y hombres de Asturias Rafael Altamira incluye también un relato corto titulado Una romería en Asturias y el idilio de un enfermo. Recordando a Palacio Valdés que, como él mismo señala a pie de página, está dedicado al autor asturiano y que constituye un claro homenaje a su novela El idilio de un enfermo. Altamira en este relato nos ofrece el retrato de dos jóvenes tísicos que, ocultando cada uno su propia enfermedad, tratan de hacer más placenteros los últimos días de la existencia del otro. Solo al final del relato los protagonistas serán conscientes de que el amor que les une es la razón de sus desvelos. El amor y la enfermedad se conjugan en esta narración para resaltar el triunfo del amor sobre la propia muerte. Relato que ya había sido incluido, bajo el título La romería, en su obra Novelitas y cuentos, Barcelona, Antonio López, Editor, Librería Espańola, Rambla del centro, no 20, s. a., 163-173. 
Con motivo de un homenaje» ${ }^{10}$, "Riverita» ${ }^{11}$, "Una novela de Palacio Valdés» ${ }^{12}$, "La hermana San Sulpicio, novela de costumbres andaluzas por Armando Palacio Valdés» ${ }^{13}$, "La fe, novela de Armando Palacio Valdés» ${ }^{14}$ y "Palacio Valdés y La hija de Natalia» ${ }^{15}$, aunque también prestaremos atención a las referencias que Altamira incluye acerca de Palacio Valdés en las secciones fijas que sobre literatura elabora para La España Moderna y para La Justicia, reseñas interesantes por estar centradas en la repercusión que la literatura espańola contemporánea, en general, y la obra de Palacio Valdés, en particular, suscitan en los países de nuestro entorno. Así, por ejemplo, el 11 de abril de 1888, aparece un artículo en La Justicia titulado «Lecturas Extranjeras. Clarín y Palacio Valdés en Italia» ${ }^{16}$. Altamira en esta ocasión centra su mirada en los juicios emitidos por el crítico italiano G. A. Cesareo, autor de El naturalismo en la novela española. En el mismo periódico, unos meses más tarde, el 16 octubre de 1888, Altamira publica "A propósito de la literatura española en Francia» ${ }^{17}$, artículo en el que alude al trabajo "La literatura española» que el crítico francés Leo Quesnel publicó el 15 de septiembre del citado año en la Nouvelle Revue y en el que destaca la importancia de Valera, Galdós y Palacio Valdés entre los novelistas españoles contemporáneos ${ }^{18}$. Igualmente, en la España Moderna, febrero de 1889, Altamira insiste en este tema en su artículo «Bibliografía española en el extranjero» ${ }^{19}$, centrándose esta vez en los juicios críticos que las dos últimas novelas de Palacio Valdés, Maximina y El cuarto poder, han suscitado en el célebre escritor y crítico americano William Dean Howells. Reflexiones que habían aparecido en la popular revista neoyorquina Harper's New Monthly Magazine, y que acogerá meses más tarde una reseña crítica firmada por el mismo crítico y dedicada a La hermana San Sulpicio, tal como Altamira señala en su Revista Literaria del 2 de diciembre de 1889 inserta en La Justicia ${ }^{20}$. En la carta que Palacio Valdés dirige a Altamira el 15 de febrero de 1889, epístola que se encuentra depositada, junto a otras nueve más, en La Residencia de Estudiantes -Fondo Altamira-, alude precisamente a estas reseñas aparecidas en la revista Harper, congratulándose de que el crítico

10. «Don Armando Palacio Valdés. Con motivo de un homenaje», en Tierras y hombres de Asturias, op. cit., pp. 203-212.

11. «Riverita, 1886", Ibid.., pp. 212-219.

12. «Una novela de Palacio Valdés. 1888», Ibid., pp. 219-226.

13. «La hermana San Sulpicio, novela de costumbres andaluzas por Armando Palacio Valdés. Dos volúmenes. Madrid. 1889", Ibid.., pp. 226-231.

14. «La Fe, novela de Armando Palacio Valdés», Ibid.., pp. 232-240.

15. «Palacio Valdés y La hija de Natalia», Ibid.., pp. 240-245.

16. "Lecturas Extrajeras. Clarín y Palacio Valdés en Italia», La Justicia, 16 de octubre de 1888 .

17. «A propósito de la literatura española en Francia», La Justicia, 16 de octubre de 1888.

18. Leo Quesnel es autor de un libro titulado, precisamente, Littérature espagnole contemporaine que se publicó en París (s.a).

19. «Notas bibliográficas: Bibliografía española en el extranjero», La España Moderna, 2 (febrero, 1888), pp. 198.202.

20. «Revista Literaria», La Justicia, 2 de diciembre de 1889. 
alicantino las dé a conocer entre el público español, dada la importancia tanto de la revista, la de mayor circulación en aquellas fechas, como por el propio prestigio del crítico neoyorquino ${ }^{21}$. El interés de Altamira por la suerte literaria de las novelas de Palacio Valdés en el extranjero es, pues, evidente, y pone de manifiesto un rasgo constante en su labor crítica, ya que Altamira siempre se preocupó tanto de mantener informados a los lectores españoles de las novedades literarias que procedían de ámbitos extranjeros ${ }^{22}$, como de difundir las creaciones literarias de nuestros autores más significativos fuera de nuestras fronteras, convencido, tal como señala en el mencionado artículo publicado en La España Moderna, de que la literatura espańola de estos ańos no se reduce a «las manifestaciones más o menos brillantes de dos o tres individualidades de talento, sino que toma ya los caracteres de una corriente social bastante señalada que llame la atención y adquiera representación propia en la esfera del

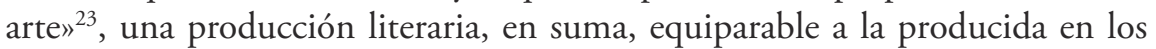
países de nuestro entorno.

La relación personal entre ambos escritores, a tenor de las cartas conservadas y recuperadas hasta el presente momento, habría que situarla, al menos, en el año 1889, ya que, además de la mencionada carta del 15 de febrero, se conocen otras dos cartas de este mismo año, una fechada el 11 de noviembre y la otra el 9 de diciembre. En ellas Palacio Valdés alienta al joven crítico alicantino a seguir trabajando, pues «conviene mucho que haya quien sepa definirla y aquilatarla [la literatura] con juicio sereno y con ilustración suficiente» ${ }^{24}$. Palacio Valdés, sin duda, conoce tanto los artículos que Altamira inserta en las páginas de $L a$ Ilustración Ibérica ${ }^{25}$ y La Justicia, como los trabajos que el crítico alicantino ha

21. Howells publicará años más tarde Familiar Spanish travels, London and New York, Harper, 1913, y es autor, asimismo, de la traducción de Un drama nuevo de Tamayo y Baus, obra que se publicó bajo el título Yorick's Love.

22. Sobre esta cuestión vid. $M^{a}$ de los Ángeles Ayala, «Rafael Altamira, difundidor de las letras europeas", en La Literatura Española del Siglo XIX y las literaturas europeas. V Coloquio de la Sociedad de Literatura del Siglo XIX, E. Rubio, M. Sotelo, M. Cristina, V. Trueba y B. Ripoll (eds.), Barcelona, PPU, 2011, pp. 17-29.

23. «Notas bibliográficas: Bibliografía española en el extranjero», art. cit., p. 198.

24. Apud., Vicente Ramos, Rafael Altamira, op. cit., p. 67.

25. Recuérdese, especialmente, el trabajo sobre la novela realista-naturalista que tempranamente publicó Altamira en La Ilustración Ibérica de Barcelona, ensayo que captó la atención de críticos tan severos como Clarín y que le permitió la publicación de sus trabajos literarios -crítica y creación- en los periódicos y revistas más prestigiosos del momento. Me refiero al titulado «El Realismo y la novela contemporánea», Año IV, 173 (24 de abril 1886), pp. 262-263 y 266; 174 (1 de mayo 1886), pp. 278-279; 176 (15 de mayo 1886), pp. 311, 314-315; 179 (5 de junio 1886), pp. 359, 362-363; 181 (19 de junio 1886), p. 399; 182 (26 de junio 1886), p. 414; 183 (3 de julio 1886), pp. 427 y 430; 184 (10 de julio 1886), 442-443 y 446; 185 (17 de julio 1886), pp. 459 y 462; 186 (24 de julio 1886), p. 467; 187 (31 de julio 1886), p. 483; 188 (7 de agosto 1886), p. 499; 189 (14 de agosto 1886), p. 515; 191 (28 de agosto 1886), pp. 550-551 y 554-555; 182 (4 de septiembre 1886), pp. 567, 570-571 y 574; 193 (11 de septiembre 1886), pp. 586-587 y 590; 194 (18 de septiembre 1886), pp. 603 y 606; 195 ( 25 de septiembre 1886), pp. 615 y 618-619; 196 (2 de octubre 1886), pp. 634-635 y 638; 197 (9 de octubre 1886), pp. 647, 650-651 y 654; 198 (16 de octubre 1886), pp. 663, 666-667 
dedicado a sus novelas Marta y María, Riverita, El cuarto poder y La hermana San Sulpicio, obras que corresponden al periodo comprendido entre 1883 y 1889. Frente a los juicios adversos que Riverita suscita entre cierto sector crítico, Clarín ${ }^{26}$ y Pardo Bazán ${ }^{27}$, especialmente, Altamira se alza en defensor de Palacio Valdés. Así, mientras los dos críticos anteriormente mencionados subrayan, en términos generales, la falta de interés que provoca la vida de Riverita, la escasez de acción y profundidad en la pintura del protagonista, Altamira considera, por el contrario, que estas condiciones suponen un acierto por parte del novelista asturiano, pues desde su punto de vista lo que Palacio Valdés pretende mostrar es un carácter tan humano como poco heroico. Se trata de presentar un hombre corriente, «uno de tantos», un muchacho que tiene ante sí abiertas infinitas posibilidades y se convierte en «ese tipo eterno de nuestro meridionalismo que, con felices disposiciones para mucho, se enclava en la reducida esfera de una celebridad de salones, ocurrente, chispeante, derrochando el ingenio en trivialidades que, de ligero en ligero, le llevan la vida toda, concluyendo por ser una medianía humana» ${ }^{28}$. No hay que buscar nada extraordinario en Riverita, no es un héroe, señala Altamira, estamos ante una historia que se desliza suavemente entre otras muchas ${ }^{29}$, sin salirse del cauce de lo común, de la vida ordinaria; el protagonista camina por la vida dejando cabos sueltos, sin pararse en un punto determinado, «abandonando caminos apenas comenzados a andar, tal como sucede en la vida real de cada vecino» ${ }^{30}$. Es evidente que para Altamira, aunque el carácter de Riverita en un primer momento pudiera parecer a veces poco verdadero, la pintura es exacta y se corresponde a la de multitud de individuos que arrastran su existencia por una esfera mediocre. De ahí que Altamira confiese que la historia le cautiva. En su reseńa crítica también destaca el valor de las descripciones tanto de ambientes - casa familiar del tío Bernardo, colegio de Nuestra Señora de la Merced...-, como de unos personajes secundarios reales y humanos -el tío Manolo, la Brigadiera, la generala Bembo, Julia, Mendoza, Hojeda, los toreros...-. Es indudable que a

y 670; 199 (23 de octubre 1886), pp. 678-679 y 682.

26. Vid. el documentado artículo de Yvan Lissorgues «Clarín y Armando Palacio: relaciones y jerarquías literarias», en Palacio Valdés. Un clásico olvidado, 1853-2003, Elena de Lorenzo Álvarez y Álvaro Ruiz de la Peña Solar (eds.), Laviana, Ayuntamiento de Laviana-Centro de Interpretación Armando Palacio Valdés, 2005, pp. 185-214.

27. Vid. el esclarecedor trabajo de Marisa Sotelo, «La crítica literaria de Emilia Pardo Bazán a las novelas de Palacio Valdés", Palacio Valdés, asturiano universal, Francisco Trinidad (ed.), Laviana, Ayuntamiento de Laviana-Centro de Interpretación Armando Palacio Valdés, 2007, pp. 327-344.

28. "Riverita», en Tierras y hombres de Asturias, art. cit., pp. 213-214.

29. Altamira señala lo siguiente a este respecto: «A veces parece borrarse algo la figura de Riverita y desmerecer el relieve; pero es que, viviendo en aquel momento en un grupo, al que resulta, como tantos otros, agregado sin significación superior, el conjunto es el que se mueve, y él quien sigue a los otros. En cuanto sale de allí, todo aquello muere ya para su historia y no vuelve a salir en ella: exactamente como en la vida real, que es una serie de cabos sueltos y de incidencias en materia de relaciones sociales» (Ibid., p. 216).

30. Ibid., p. 213. 
Altamira el relato le atrae, lo que no impide que ponga de manifiesto algún que otro reparo. Así, al analizar el final de la novela, señala que el idilio amoroso entre el protagonista y Maximina resulta un tanto romántico y a todas luces forzado, difícil de creer y sentir. Para Altamira Riverita en su conjunto no tiene el empuje de Marta y María, ni presenta una acción cerrada como El idilio de un enfermo o José. Sin embargo, dado su carácter episódico, abierto, Palacio Valdés tiene la posibilidad de ofrecer no sólo el retrato del protagonista, sino una envidiable galería de personajes secundarios. De ahí que, desde su punto de vista, "Riverita se impone, y seduce y se lee de corrido" ${ }^{31}$.

En términos generales Altamira manifiesta siempre un extraordinario interés por las novelas del asturiano, pues, como él mismo confiesa en innumerables ocasiones, reúne unas notas que coinciden con sus propias preferencias como narrador: esa sátira "suave y pulquérrima en la forma, pero sangrienta, certera en el fondo, que no todos saben manejar con la discreción que de suyo pide» ${ }^{32}$, el carácter sentimental de los relatos y la hermosura lograda en la pintura de paisajes, escenas y tipos. Notas que si bien están presentes en El cuarto poder, no le impiden considerar a esta novela inferior a sus hermanas mayores. Altamira señala que Palacio Valdés ha enlazado dos acciones principales; por un lado la pintura de la vida local de Sarrió, "con sus luchas intestinas, sus murmuraciones, sus riñas de vecindad puestas al relieve con la aparición del cuarto poder, la prensa, en la población» ${ }^{33}$ y, por otro, los amores de Gonzalo y el drama de su casamiento. Para Altamira la primera parte, la correspondiente a la descripción de la sociedad sarriense, es deliciosa, resplandeciendo en ella el verbo satírico de Palacio Valdés, aflorando su habilidad para mostrar el lado ridículo de las cosas. De ese vasto cuadro social destaca la magnífica pintura de Don Benigno Belinchón, el progresista y fundador del primer periódico de la localidad, tipo que le recuerda al personaje galdosiano Benigno Cordero, pues si éste lucha con las armas de miliciano en pro de sus ideales, Belinchón lo hará también con sus escritos. Para Altamira la segunda parte de la novela no está a la altura de la primera. Aprecia que la acción carece de relieve, que el novelista no la siente, que es postiza, mientras los caracteres de Cecilia y Ventura, esas dos hermanas de temperamento tan opuesto, adolecen de la fuerza necesaria. No obstante, a pesar de estos defectos, Altamira recomienda su lectura tanto por la gracia con que está escrita como por el reflejo de la vida provinciana que en ella subyace.

La siguiente novela reseñada por Altamira es La hermana San Sulpicio, el relato que tantas satisfacciones proporcionó a su autor. Altamira destaca, fundamentalmente, la capacidad de Palacio para condensar «sus observaciones de viajero y artista, dándoles vida y movimiento al compás de una acción dramática inventada con acuerdo excelentes ${ }^{34}$. En muy pocas ocasiones,

31. Ibid., p. 219.

32. «Una novela de Palacio Valdés. 1889», en Tierras y hombres de Asturias, art. cit., p. 220.

33. Ibid., p. 221.

34. «La hermana San Sulpicio. Novela de costumbres andaluzas por Armando Palacio Valdés», 
continúa Altamira, un autor "ha sabido presentar con tanto arte y con amenidad tan sencilla el resultado de su observación y estudio sobre la vida de un pueblo que, por muchas razones, puede llamarse para él extraño» ${ }^{35}$. Altamira considera un acierto la forma autobiográfica elegida, pues de esa manera quien habla es un gallego que se enamora de una andaluza. Palacio consigue de esta forma un contraste muy artístico, porque así «las observaciones del gallego -vecino de Asturias- alcanzan a todas las manifestaciones de una vida tan distinta de la del país galaico como la andaluza, y tienen mayor relieve» ${ }^{36}$. Ese choque de temperamentos e ideas entre el gallego y la sevillana arrebatada y ardiente reflejan, para Altamira, las diferencias más notables y generalizadas entre ambas zonas geográficas. Los amores, que son el fondo de la acción novelesca, le parecen interesantes a Altamira, pero sobre todo lo que le admira es la impresión total de la vida andaluza que resulta de su lectura, impresión que compara a la que el viajero experimenta tras una placentera estancia en lugares distintos a su entorno habitual. Sevilla es para Altamira la verdadera protagonista de la novela, de ahí que, consecuente con esta idea, en su estudio prescinda del análisis de los personajes. La reseńa concluye, no sin antes censurar la inclusión de algunas frases populares demasiado vulgares y destacar la constante ironía, la burla fina e intencionada que tanto le agrada, con la promesa de un nuevo trabajo dedicado al importante prólogo que precede a La Hermana San Sulpicio, estudio que, si lo escribió, hasta el momento no se ha localizado, pues solo hemos hallado una escueta referencia al mencionado prólogo en el artículo en el que se recogen las opiniones de Howells sobre La Hermana San Sulpicio.

Frente a la grata acogida con que $L a F e$ fue recibida por parte de algunos críticos, Clarín y Deschamps ${ }^{37}$, especialmente, Altamira muestra algunas reticencias, aunque su ecuanimidad nunca le permita acercarse a las duras censuras emitidas desde las páginas de La Época o La España Moderna. Altamira sitúa $\mathrm{La} F$ e dentro de las novelas psicológicas, de esas narraciones que se caracterizan por su escasez de acción y que centran su mirada en lo más íntimo de ser humano, los conflictos que bullen en su interior. Análisis que Palacio Valdés, escasamente contemplativo y de natural satírico, mezcla con una acción muy movida y pintoresca, «que quita algo de efecto y continuidad al psicologismo del padre Gil» ${ }^{38}$ y le alejan de otras obras en las que se narra el proceso de la lucha de creencias. La elección de un sacerdote de espíritu sencillo, de escasa preparación intelectual, que apenas sabe de nada y que se lanza ávidamente a unas lecturas para las que no está preparado para recuperar la fe, le parece poco acertado, pues desde su punto de vista, si se hubiese tratado

en Tierras y hombres de Asturias, art. cit., p. 228.

35. Ibid., p. 229.

36. Ibid., p. 229.

37. Vid. a este respecto Ángel Cruz Rueda, Armando Palacio Valdés. Su vida y su obra, Madrid, S.A.E.T.A., 1949, $2^{\text {a }}$ ed., pp. 122-123.

38. "La Fe, novela de Armando Palacio Valdés», en Tierras y hombres de Asturias, art. cit., p. 234. 
de un sacerdote de gran cultura al lector le hubiese sido más fácil seguirlo en su evolución espiritual. Altamira señala, por ejemplo, que «La crisis religiosa de Renan -que él cuenta tan sincera y profundamente en sus Recuerdos- la comprende muy bien todo hombre culto" ${ }^{39}$. Sin embargo, el padre Gil, un hombre poco atento a los términos rigurosamente científicos del problema de la creencia, solo por un acto de fe puede volver a creer. Lo importante no era demostrar la verdad de sus creencias, lo interesante era mostrar el efecto que produce esa fe en su ánimo, en su conducta. Algo que no está totalmente logrado en la novela de Palacio Valdés desde su punto de vista.

Altamira se detiene en otros aspectos del libro que, si bien dañan al proceso psicológico narrado, para el crítico alicantino suponen el mayor mérito artístico, el más personal de Palacio Valdés: la inclusión de la nota dramática, que se aprecia, por ejemplo, en esa escena en la que se recrea el amor de don Álvaro a su esposa la noche en la que Joaquina regresa; la descripción exacta de la vida rural que hallamos en la visita del padre Gil al cura labriego don Restituto - «Pocas veces desde Los pazos de Ulloa y La madre Naturaleza, de Emilia Pardo, he leído descripción más exacta de la vida rural... de los rurales que lo son de alma y cuerpo» ${ }^{40}$; las escenas cómicas de la sociedad peñasca, no exentas algunas de cierta exageración, le parecen un total acierto. Elementos, en suma, que dotan al relato de gran amenidad. De ahí que Altamira señale que $\mathrm{La} \mathrm{Fe}$ ofrece el raro fenómeno de «tocar un problema trascendental, como dicen las gentes, y ser a la vez un libro amenísimo; por tanto accesible a muchos lectores ${ }^{41}$.

Tras la reseña de $L a F e$ no volvemos a encontrar un nuevo artículo de Altamira hasta que se celebra el homenaje a Palacio Valdés en Oviedo el 5 de abril de 1906, sumándose de esta forma Altamira a este rendido reconocimiento. El artículo, «Don Armando Palacio Valdés. (Con motivo de un homenaje)», que presumiblemente aparecería en la prensa, será recogido primero en Arte y realidad ${ }^{42} \mathrm{y}$, posteriormente, en Tierras y hombres de Asturias. Artículo interesante porque ofrece la visión sintética de un crítico que atentamente ha ido siguiendo la trayectoria literaria del novelista asturiano. Altamira rememora cómo admiraba a Palacio Valdés cuando era un simple estudiante que recorría los claustros valencianos cargado de las novedades literarias, época en la que ya consideraba a Palacio como uno de los grandes «maestros». Altamira resalta los aspectos más característicos y permanentes del corpus narrativo: «el fondo

39. Ibid., p. 235.
40. Ibid., p. 238.

41. Ibid., p. 234. Otros aspectos negativos de menor calado que encuentra Altamira en la novela son los numerosos descuidos gramaticales que afean el texto. Tampoco le parece verosímil la figura de Obdulia, construida "con puros datos científicos de Les maladies des mystiques y otras obras análogas», Ibid.., p. 238, o algunos episodios poco convincentes, como cuando el padre Gil, hombre temeroso y débil, imprudentemente acompaña a la hija de Osuna en su premeditada escapada.

42. Rafael Altamira y Crevea, «Don Armando Palacio Valdés. Con motivo de un homenaje», en Arte y realidad, Barcelona, Editorial Cervantes, 1920, pp. 107-114. 
satírico de sus cuadros de costumbres, realistas, vivos siempre, unido a la delicadeza con que sabe sentir la poesía del hogar, de la vida de familia y la del campo ${ }^{43}$. Frente a la opinión del crítico inglés Fitzmaurice-Kelly, expresada en la última edición francesa de su Historia de la literatura española ${ }^{44}$, que subraya, además de la habilidad y firmeza en la construcción novelística y la energía que imprime a la pintura de los caracteres - notas con las que está de acuerdo-, su acercamiento al Naturalismo, Altamira sostiene, por el contrario, que lo más constante en las novelas de Palacio Valdés es la serenidad y suavidad en su arte, la sátira, nunca agria o épica como en Zola, sino humorística, como lo es nuestra literatura picaresca. Condiciones que justificarían por ellas mismas la gran aceptación que las novelas de Palacio Valdés tienen en el mundo anglosajón, lectores cuyas preferencias se sitúan lejos de las grandes explosiones trágicas y de las fiebres pasionales naturalistas. Altamira defiende, pues, la originalidad de la narrativa de Palacio Valdés frente al Naturalismo francés.

Igualmente, subraya que Palacio Valdés no es un costumbrista local a la manera de Pereda que, enamorado de su tierruca, se complace en retratarla punto por punto, pues, aunque asturiano, Palacio Valdés es capaz de pintar la sociedad andaluza o la levantina con la misma maestría que si se tratara de reflejar la suya propia. Donde más se muestra el carácter asturiano del novelista es en el humor y en la sátira, ya que posee el finísimo instinto, propio de la gente asturiana, de saber dar bromas colectivas, "con una apariencia de seriedad que despista a los que no le conocen, pero que chorrea burla por todos lados» ${ }^{45}$. Un humor que, como se ha dicho a propósito del Quijote, es más revolucionario que el ceño y la violencia.

Altamira concluye el artículo señalando la modernidad y compromiso de los asuntos planteados en las novelas de Palacio Valdés: el conflicto de la vida beata y la vida del hogar en Marta y María, el problema religioso en $\mathrm{La} \mathrm{Fe}$, la problemática social en La espuma, la cuestión política en Riverita, Maximina y El cuarto poder..., afirmando de forma categórica que «cuando se escriba la historia literaria de las ideas en la literatura española -en parte ya esbozada, aunque con limitado punto de vista en los Heterodoxos de Menéndez Pelayo-, Palacio Valdés ocupará un sitio al lado de los combatientes por la libertad, la justicia y la cultura» ${ }^{46}$.

Entre 1906 y 1924 Altamira no vuelve a escribir ningún artículo sobre la obra de Palacio Valdés. Sin embargo, las relaciones personales se mantienen, pues contamos con dos cartas de 1916-17 de octubre y 21 de noviembre en las que se aprecia que la amistad entre ambos se ha estrechado considerablemente.

43. «Don Armando Palacio Valdés. Con motivo de un homenaje», en Hombres y tierras de Asturias, art. cit., p. 207.

44. La obra de Fiztmaurice-Kelly se publicó en España en 1901. Historia de la Literatura española desde los origenes hasta el año de 1900. Traducida del inglés y anotada por Adolfo Bonilla y San Martín, con un estudio preliminar por M. Menéndez Pelayo, Madrid, La España Moderna, 1901.

45. Ibid., p. 210.

46. Ibid., p. 211. 
En la primera de ellas, Palacio Valdés reitera a Altamira la imposibilidad, por asuntos de familia, de formar parte del comité español que se trasladará a Francia para corresponder a la visita que un grupo de intelectuales franceses había realizado España ese mismo año, a pesar de haber recibido la invitación oficial desde el Instituto de Bordeaux. La carta concluye deseando que las relaciones entre Francia y España se intensifiquen con esta iniciativa. Palacio Valdés se refiere a la visita que un grupo de intelectuales, entre los que se encuentra Altamira, realizaron a Francia en 1916 y que dio lugar a la creación el 25 de noviembre en Madrid del Comité «Aproximación franco-española». La fechada en noviembre es también interesante, pues encontramos la referencia a su nombramiento como miembro de honor de la Royal Society of Literature de Londres. Palacio Valdés se muestra muy humano, ya que, después de sostener que no es muy sensible a las distinciones honoríficas, muestra su preocupación por no haber recibido el diploma e insta a Altamira a averiguar si su carta de aceptación del nombramiento se ha extraviado o no. La epístola termina con un comentario que evidencia su posición a favor de los aliados, pues señala, tras congratularse por los óptimos resultados obtenidos por la expedición a Francia, que no saben los germanófilos españoles lo mucho que les van a deber cuando termine la guerra.

En las restantes cartas conservadas encontramos alusiones concretas a determinados acontecimientos, como, por ejemplo, en la fechada el 1 de mayo de 1924, donde Palacio Valdés alude a la frustrada candidatura de Altamira a la Real Academia Española. Palacio Valdés, dando por sentado que Altamira conoce cómo se han desarrollado los hechos a través de Serafín Álvarez Quintero ${ }^{47}$, ratifica que fue Antonio Maura, director de la Real Academia Española, el que estaba totalmente decidido a que fuera Azorín y no Altamira el que ocupara el sillón vacante dejado por el fallecimiento de Juan Navarro Reverter. Palacio Valdés cede, al igual que Serafín Álvarez Quintero, ante estas presiones, obteniendo a cambio la promesa de contar con los votos que llevan a Azorín a la Academia para que Altamira ocupe la próxima vacante. Carta en la que además agradece el último artículo que Altamira le ha dedicado. Se trata, sin duda, de la reseña dedicada a La hija de Natalia, donde Altamira de nuevo muestra su admiración por el arte narrativo de su amigo. En el artículo mencionado se alude a las frecuentes conversaciones mantenidas entre ambos en estos años, y en las que Altamira le insta a que escriba, tras la publicación de $L a$ novela de un novelista, un segundo volumen de memorias. Asimismo señala que el propio Palacio Valdés califica a La hija de Natalia de novela de amor, dando constancia de las inseguridades del novelista, ya que consideraba un riesgo excesivo el escribir de amor a los setenta años, «porque ese asunto difícilmente

47. Vicente Ramos, en Rafael Altamira, op. cit., p. 226, recoge un fragmento de la carta enviada por Serafín Álvarez Quintero a Altamira el 11de abril de 1924: «[...] debo decirle que la candidatura de usted en la Academia hubiera en su día aventajado en votos a la otra que se le opone, a juzgar por lo visto y oído; pero, a pesar de ello, por razones de oportunidad y de prudencia, y por otras de delicadeza que a mí se refieren, he creído lo mejor dejar hecha la siembra y ofrecer el campo libre al contrincante...». 
se puede sentir a esa edad con la vibración que pide su expresión artística» ${ }^{48}$. Altamira pretende difuminar sus temores, y los de sus posibles lectores, al señalar que, para el novelista, «el amor puede ser (y lo es en muchos) un tema lírico que podría haberse vivido personalmente y reflejado luego en libro, como en el caso de Werther de Goethe; pero también puede ser un tema épico de pura observación externa que, sin la menor emoción personal por parte del escritor, le haga penetrar hasta el fondo del alma de los individuos observados y producir una obra llena de verdad y de color sentimental ${ }^{49}$ y eso es lo que desde su punto de vista ha alcanzado Palacio Valdés en esa novela de una mujer ${ }^{50}$, según la califica el propio Altamira, que recoge lo mejor de sus calidades literarias -interés narrativo, ironía suave, serena contemplación de las relaciones humanas.

Del contenido de las restantes cartas depositadas en la Residencia de Estudiantes cabe señalar que buena parte de ellas carecen de fecha. No obstante, algunas de ellas, por aludir a algún hecho concreto, se pueden situar con total precisión. Esto sucede, por ejemplo, con una carta en la que Palacio Valdés otorga su consentimiento, en calidad de Presidente del Ateneo madrileño, para que Altamira pronuncie una serie de conferencias en él. Se trataría del ciclo de conferencias que bajo el título Funcionamiento y problemas actuales de la Justicia Internacional Altamira dictó en la segunda quincena de diciembre de 1924. En otras ocasiones, sin embargo, la fijación temporal es más problemática, pues se trata de meras respuestas a cartas de agradecimiento cursadas por Altamira por su interés por algún asunto que no se especifica, o bien, acuse de recibo y agradecimiento por parte de Palacio Valdés por el envío de un artículo escrito por Altamira. En estos casos, solo el membrete de la Real Academia Española permite una mínima, pero insuficiente, datación de las mismas. Mayores dificultades de fijación presenta una carta de Palacio Valdés que carece, incluso de membrete, en la que responde a la invitación cursada por Altamira para que publique su nueva novela en las páginas de un periódico. Palacio Valdés se excusa pues, tal como él mismo señala: la redacción de la novela no está concluida y tampoco sabe determinar el tiempo que necesita para finalizarla. Parece referirse a la redacción de una novela extensa porque Palacio señala que dadas las reducidas dimensiones del periódico, este no le parece el lugar idóneo para su publicación.

48. «Palacio Valdés y La hija de Natalia», en Tierras y hombres de Asturias, art. cit., p. 243.

49. Ibid., p. 243.

50. En el artículo Altamira rebate la calificación de La hija de Natalia como novela de asunto político emitida por un crítico anónimo en fechas recientes, definiéndola como novela de una mujer. Desde su punto de vista aunque en sus páginas aparezca la circunstancia de que el padre de la protagonista sea un ministro y que su muerte esté provocada por «una de esas chacarrerías que la vida política produce a menudo y seguirá produciendo", ibid., p. 242, no se puede deducir que Palacio Valdés deseara escribir sobre la política. La inclusión de asuntos políticos, como en otras novelas del escritor asturiano, hay que considerarla un episodio más en la historia de Natalia. 
Para finalizar quisiéramos centrarnos en una carta fechada el 25 de abril de 1927, carta que Palacio Valdés envía a Rafael Altamira agradeciéndole las gestiones llevadas a cabo para que su propuesta como candidato al premio Nobel llegase a buen término. Palacio Valdés confiesa que ya conocía por indicación de un miembro de la propia Academia sueca que la propuesta había sido presentada fuera de plazo. Probablemente Palacio Valdés tenía conocimiento del contenido de la carta que Altamira dirigió el 5 de abril al secretario de la Academia Sueca, epístola interesantísima ${ }^{51}$, pues por un lado muestra el interés de Altamira por sacar adelante la candidatura de Palacio Valdés y por otro, porque en ella encontramos sintetizados los méritos literarios que, desde el punto de vista del crítico alicantino, avalan de manera clara la propuesta. Altamira desde su calidad de catedrático de la Universidad de Madrid, miembro de la Real Academia de la Historia y de la Real Academia de Ciencias Morales y juez de la Corte Permanente de Justicia Internacional de La Haya, da fe pública al Secretario de la Comisión del Premio Nobel del lugar preeminente que ocupa Armando Palacio Valdés, muerto Galdós, entre los novelistas españoles contemporáneos, destacando, al igual que en otras muchas ocasiones anteriores, los mejores logros del novelista asturiano, como su cuidado lenguaje, su técnica narrativa, su capacidad para observar la realidad y mostrar con total acierto la vida rural y burguesa de Asturias y Andalucía, la delicadeza de los asuntos sentimentales que en sus novelas se refleja o el estudio de la conducta moral del hombre, entre otros muchos aciertos. Altamira concluye su carta haciendo hincapié en el reconocimiento europeo que ya tiene la obra de Palacio Valdés ${ }^{52}$, pues, tal como afirma, no es solo el novelista español más traducido, sino que en ocasiones la expectación que despiertan sus novelas en el ámbito anglosajón lleva a que estas hayan aparecido antes en lengua inglesa que en lengua española.

Tras la lectura de todas estas reseñas críticas y de las cartas conservadas ${ }^{53}$ es evidente el enorme interés que la obra narrativa de Palacio Valdés siempre despertó en Rafael Altamira, un crítico incisivo y perspicaz que supo apreciar en todo momento sus méritos literarios y situar a Palacio Valdés entre los grandes novelistas del realismo-naturalismo español.

51. La mencionada carta me ha sido facilitada generosamente por D. Francisco Trinidad y se halla depositada en el Centro de Interpretación Armando Palacio Valdés.

52. Vid. a este respecto $M^{a}$ de los Ángeles Ayala, «Recepción de la obra de Palacio Valdés en Europa», en La Literatura Española en Europa. 1850-1914, Ana Ma Freire López y Ana Isabel Ballesteros Dorado (coords.), Madrid, UNED, 2017, pp. 25-40.

53. En el Centro de Interpretación se conserva una carta de Rafael Altamira dirigida a Palacio Valdés desde Madrid el 15 de enero de 1928. En ella el crítico alicantino muestra su satisfacción por los agasajos y homenajes recibidos por el autor asturiano en los últimos meses. Asimismo le expresa su sincero agradecimiento por el placer que a lo largo de tantos años le ha producido la lectura de sus novelas, desde que descubriera El señorito Octavio cuando todavía era un adolescente. Altamira se despide de su amigo no sin antes manifestar su deseo de que en este año, 1928, «los del Nobel cumplan su promesa». 
